\title{
IMPROVING CHINA'S P2P LENDING REGULATORY SYSTEM: AN EXAMINATION OF INTERNATIONAL REGULATORY EXPERIENCE
}

\author{
Lei Xiao*
}

\begin{abstract}
Peer-to-peer (P2P) lending is an important source of funding for businesses and individuals. Today, China represents the largest $P 2 P$ lending market in the world, despite having no clear regulatory policies. In 2015, some $34.5 \%$ of China's P2P lending platforms experienced serious problems, including owners vanishing, fraud, and difficulties with cash withdrawal. So, the proper regulation of the $\mathrm{P} 2 \mathrm{P}$ lending industry is both important and urgent. $P 2 P$ lending has certain distinctive advantages and also has associated risks. When combined with the economic and regulatory environment, the risk involved in China's $P 2 P$ lending becomes more complicated. Without a comprehensive credit system, China's P2P lending platforms started to provide guarantees to investors, which actually violate the related laws on guarantees. More importantly, the lending platforms' role changed from information intermediaries to credit intermediaries, causing regulatory arbitrage. Platforms engage in quasibanking businesses but are not restricted by relevant requirements of banks. To improve $\mathrm{P} 2 \mathrm{P}$ lending regulation, academics in China began to focus on international $\mathrm{P} 2 \mathrm{P}$ lending regulatory experience as a reference point for reform. Some have suggested that China should merge all existing regulatory entities to form a unified regulator like the Financial Conduct Authority (FCA). However, to reduce regulatory arbitrage, functional regulation is an appropriate direction for reform, although it does not necessarily require the adoption of a single-regulator model. Multiple regulatory entities can also oversee $\mathrm{P} 2 \mathrm{P}$ lending, depending on the activities that fall within their regulatory authority. In order to improve China's P2P lending regulatory system, the government should adopt an encouraging and supportive attitude towards this emerging industry, considering its important function in providing financial resources for fundthirsty small- and medium-sized enterprises and individuals. Functional regulatory theory should be adopted to ensure that similar financial services receive the same regulation, as well as to reduce regulatory arbitrage and unfair competition.
\end{abstract}

INTRODUCTION......................................................................4 461

I. THE SPECIAL CHARACTERISTICS OF CHINA's P2P LENDING INDUSTRY ...462

II. The NECESSity OF REGULATION...................................................463

\footnotetext{
* Lei Xiao, Senior Staff Member of the Legislative Affairs Office of Hunan Provincial Government, China; LLM, The University of Leeds (2015); No.8 Xiangfu East Road, Changsha, China, 410004. Research field: Business Law.
} 
III. SHOULD CHINA ESTABLISH A UNIFIED REGULATOR LIKE THE FCA?......465

IV. INSTITUTIONAL REGULATION OR FUNCTIONAL REGULATION .................465

V. SUGGESTIONS FOR P2P LENDING REGULATION IN CHINA ........................470

A. Encourage Financial Innovation ..............................................470

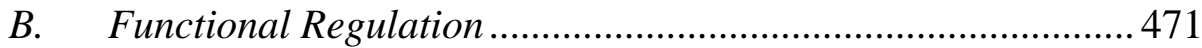

C. Improve the Credit Rating Environment to Reduce Guarantees....

\section{INTRODUCTION}

Peer-to-peer (P2P) lending, as an innovative, decentralised and alternative means of finance, has become an important source of funding for individuals, businesses, and organisations that struggle to access funds from traditional financial institutions. ${ }^{1} \mathrm{P} 2 \mathrm{P}$ lending provides early-stage investments to start-ups as well as growth capital to small- and mediumsized enterprises (SMEs). Robert J. Shiller, the 2013 Nobel Prize in Economics winner, states that a "good society" is also financially democratic. That is, everyone should have access to the same products and services. ${ }^{2}$ Furthermore, universal human rights include the right of everyone to fair financial arrangements, while the world would arguably be a better place with more democratic access to financial markets. Shiller believes that we need more financial innovation, and that financial institutions should play a larger role in helping society to achieve its goals. ${ }^{3}$

Shiller's arguments clearly speak to the nature of the P2P lending industry. P2P lending originated in the UK, although it has reached its highest peak in China. While the majority of P2P platforms facilitate "quasibanking" businesses, their risk control operations are of a much lower quality when compared to those of traditional banks. Moreover, potential risks are increasing in the $\mathrm{P} 2 \mathrm{P}$ lending industry due to deficient internal management and loopholes in the regulatory system. In 2015, there were 896 problematic P2P lending platforms, accounting for $34.5 \%$ of the total number of China's P2P lending platforms (including owners vanishing, fraud, and capital chain issues that resulted in difficulties with cash withdrawal). ${ }^{4}$ To a certain extent, these problems endanger investor

\footnotetext{
${ }^{1}$ Martin Campbell, History in the Making: The Rise of Peer-to-Peer Lending, 11 E-FInANCE \& PAYMENTS LAW \& POLICY 4 (2010).

${ }^{2}$ Robert J. Shiller, FinANCE AND the Good Society 40 (Princeton University Press 2012).

${ }^{3}$ Ibid at150.

${ }^{4}$ Annual Report of China’s P2P Industry (2015). http://www.wdzj.com/news/baogao/25555.html (last visited May 23, 2016).
} 
confidence and have an adverse effect on P2P lending, thus posing a threat to the development of the P2P lending industry as a whole.

\section{THE SPECIAL CHARACTERISTICS OF CHINA’s P2P LENDING INDUSTRY}

In general, P2P lending refers to lending activities on the internet, with P2P platforms representing funding channels for both borrowers and investors. From the original meaning of P2P lending, platforms should operate as pure information intermediaries. That is, they should not become deeply involved in lending activities such as providing guarantees on principal and interest. In practice, most British P2P lending platforms operate as pure platforms without guarantees. ${ }^{5}$ Furthermore, all P2P lending operations are conducted online, which greatly improves the efficiency of resource allocation. P2P lending platforms also quickly match lenders and borrowers online, highlighting their user-friendliness, payment convenience, and information transparency. ${ }^{6}$ However, due to the rigid financial licensing regime and credit resource control of the country, P2P lending in China has produced different models, some of which have diverged from the original model by abandoning both the "pure information intermediary" and "online operation” principles. This greatly increases risk and in turn presents significant challenges to regulators.

China currently has no comprehensive personal credit rating system. ${ }^{7}$ The central bank credit system is not open to the P2P industry, while the commercial credit industry has only recently been established. Thus, P2P lending platforms have to build their own credit rating systems, which requires a large credit rating team to collect, analyse, and appraise credit materials. Credit collection takes a large amount of time and energy, making up the main cost of operating a P2P lending platform. This not only reduces the efficiency of loan activity, but also enhances the marginal costs of $\mathrm{P} 2 \mathrm{P}$ lending, making P2P lending a labour-intensive business where developing a new customer requires significant human resource expenditure. ${ }^{8}$

Even when paying a high price for credit collection, the quality of a credit rating cannot be guaranteed, as offline credit collection is a subjective

\footnotetext{
${ }^{5}$ Emily Reid and James Black, The Future for Peer-to-Peer (P2P) Lending: The Proposed Regulatory Framework for Lending Platforms, 29 BUTTERWORTHS JOURNAL OF INTERNATIONAL BANKING \& FINANCIAL LAW 38 (2014).

${ }^{6}$ Xusheng Yang, P2P's Unbridled Growth 30 International FinanCial Law Review 23 (2014).

${ }^{7}$ Robert C. Feenstra, Exports and Credit Constraints under Incomplete Information: Theory and Evidence from China, THE REVIEW OF ECONOMICS AND STATISTICS 733 (2014).

${ }^{8}$ Yiling FinANCE, White BoOK ON ChinA’s P2P Lending IndustRy 145 (China Economic Publishing House 2014).
} 
affair. Different platforms have different procedures and criteria, and different credit rating team members practice different styles. In the UK, owing to the existence of a sound credit rating system, defaults would result in high costs for borrowers. In China, the absence of a credit rating system will lead to low default costs and high debt collection costs. If a P2P lending platform presents itself as a pure information intermediary without offering any guarantees, it will be hard to attract investors, since the poor credit environment will make the possibility of default high. Therefore, the majority of China's P2P lending platforms currently include expressed or implied guarantees on the principal and interest of any loan, which leads to the tendency to strengthen a platform's liability and weaken the relationship between lenders and borrowers. China's P2P lending has thus evolved from "pure information intermediaries" to "credit intermediaries" in this manner. ${ }^{9}$

\section{THE NECESSITY OF REgULATION}

Today, China is the largest P2P lending market in the world. ${ }^{10}$ Aside from the market's distinct nature, regulatory arbitrage (i.e., when market competitors take advantage of loopholes in regulatory systems to avoid certain kinds of regulations) ${ }^{11}$ is a significant reason for the explosive growth of China's P2P lending industry.

P2P lending offers a "quasi-banking" business to the general public, although there is no regulator or regulation for such lending in China. Compared to the traditional banking industry, the P2P lending industry has a low risk control ability and an inadequate internal management capacity. ${ }^{12}$ Due to increasing computer and information technology progress, the market access threshold of P2P lending is excessively low, which results in non-financial organisations rapidly engaging in financial business enmasse. When applying different regulatory policies to similar financial services, this inevitably results in regulatory arbitrage, unfair competition, and systemic risks. In fact, traditional financial organisations, such as banks, increasingly complain about why, in providing the same loan services, P2P lending platforms do not need licenses and have to meet no specific

\footnotetext{
${ }^{9}$ P. Xie, China's P2P Lending: Market, Organizations and Models 233 (China Financial Press 2015).

${ }^{10}$ The Market Size of China's P2P Lending Industry in 2015 was about 98 Billion British Pounds. Annual Report of China’s P2P Industry (2015). http://www.wdzj.com/news/baogao/25555.html (last visited May 23, 2016).

${ }^{11}$ Adrian Doble and Geoff Carton-Kelly, Regulatory Arbitrage: Consequences for the European Restructuring Community, 11 INTERNATIONAL CORPORATE RESCUE 3 (2014).

${ }^{12}$ Ping Xie, China’s P2P Lending: Market, ORganizations And Models 244 (China Financial Press 2015).
} 
requirements. Their argument is that if market competitors engage in the same financial service, they should in principle receive the same regulation. ${ }^{13}$ Aside from this issue, large amounts of money have been channelled into underground or speculative activities in China. Without proper regulation, the $\mathrm{P} 2 \mathrm{P}$ lending industry may transfer risks to the banking industry and the wider economy, thus endangering social stability. ${ }^{14}$

Several commentators have suggested that there is no need to regulate P2P lending, since their loan contracts are between borrowers and lenders. Furthermore, these platforms only provide services related to the sifting, credit rating, and after-loan services of borrowers, thus existing merely as a hub of private lending. ${ }^{15}$ However, this view overlooks the fact that such platforms play more of a role in financial services than as mere information intermediaries. For instance, to mitigate risk, most platforms have a mechanism to disperse capital to a certain number of borrowers or divide a loan into many parts and offer it to many investors, which is similar to bond-like financial products. More importantly, an increasing number of platforms in China have begun to provide guarantees for investments. These platforms also provide credit ratings and investment and financial consulting services. In terms of promotions, many P2P lending platforms compare their products with bank deposits, financial products, bonds, and stocks to attract clients with the promise of low risk and high reward. ${ }^{16}$

While the question of whether P2P lending platforms should be deemed financial organisations is still controversial, there is no denying that they play a quasi-banking role in China at present. Without appropriate regulation similar to that of traditional financial organisations, P2P lending may present serious risks. However, some commentators excessively emphasise the function of "survival of the fittest in the market". ${ }^{17}$ Theoretically speaking, if there is enough commercial opportunity, given brutal market competition, large companies with sound governance should emerge. Yet, during the evolution process, social trail costs and error costs will be paid. ${ }^{18}$ Regulation is able to reduce such costs and prevent risk dissemination. As discussed earlier, China's P2P lending industry has

\footnotetext{
${ }^{13}$ Xiaopu Zhang, Exploring the New Regulation Model for the Internet Finance, CHINA BANKING REGULATORY COMMISSION WORKING PAPER 235 (2014).

${ }^{14}$ YiLing FinANCE, INTERNET FinANCE 356 (Electronic Industry Press 2014).

${ }^{15}$ Rui And Liu, China Internet FinAnce Development RePort 435 (Social Science Academy Press 2014).

${ }^{16}$ Peter Yeoh, Implications of Online Funding Regulations for Small Businesses, 22 JouRNAL OF FinANCIAL REgULATION \& COMPLIANCE 354 (2014).

${ }^{17}$ Rui And Liu, China InTernet FinAnce DeVelopment RePort 435 (Social Science Academy Press 2014).

${ }^{18}$ Ibid.
} 
splintered into different business models, some of which no longer merely play the role of an online intermediary. Apart from causing systematic financial risks, the risks of $\mathrm{P} 2 \mathrm{P}$ lending also include fraud, money laundering and repeat lending.

\section{SHOULD CHINA ESTABLISH A UNIFIED REGULATOR LIKE THE FCA?}

There have been calls for China to adopt a "single regulator" or "integrated regulation" model much like the FCA in the UK. It has even been suggested that China should transfer immediately to the UK regulatory model by merging the existing financial regulatory agencies into a single regulatory body. ${ }^{19}$ The emergence of the P2P lending industry and other innovative financial products pose a serious challenge to China's traditional sector-based mode of regulation, under which regulatory responsibility is divided by the traditional boundaries of banking, securities, and insurance. An increasing number of banks have complained about the unfair competition of $\mathrm{P} 2 \mathrm{P}$ lending platforms, as the latter provide almost the same products yet have no requirements in terms of licensing, capital adequacy ratio, and so forth. It is therefore necessary to consider in-depth the above calls for reform, especially with reference to the history of P2P lending regulations in the UK. Such a proposal is supported by functional regulation theory, which is opposed to institutional regulation theory (both of which will be discussed in the following). China must analyse the advantages and disadvantages of both theories that support sector-based and unified regulator models before seeking to answer the following question: If China was to choose a functional regulatory model, does it necessarily require a unified regulator like the FCA?

\section{INSTITUTIONAL REGULATION OR FUNCTIONAL REGULATION}

Institutional regulation serves to divide up regulatory power among regulatory bodies according to specific types of financial business, such as banking, securities, and insurance. The same financial entities should be regulated by the same regulator. ${ }^{20}$ According to this theory of regulation, regulators are intended to mainly focus on financial entities' activities rather than their products or services. For instance, the activities of commercial

\footnotetext{
${ }^{19}$ P. Xie, China's P2P Lending: Market, ORganizations and Models 245 (China Financial Press 2015).

${ }^{20}$ Leonardo Giani, An Orderly Liquidation Authority within a Disorderly Supervisory Framework: Looking into the Dodd-Frank Act from Europe, EUROPEAN COMPANY AND FINANCIAL LAW REVIEW 110 (2014).
} 
banks are to be supervised by the China Banking Regulatory Commission (CBRC) regardless of whether the products or services provided by banks are loans, securities, or insurance. China adopted an institutionally-based regulatory model in 1992, which made the China Banking Regulatory Commission responsible for regulating commercial banks and trust investment companies, the China Securities Regulatory Commission (CSRC) responsible for regulating securities companies and fund companies, and the China Insurance Regulatory Commission (CIRC) responsible for regulating insurance companies. This sector-based regulatory regime corresponds to the segmentation of financial services and markets in China. ${ }^{21}$

China's adoption of institutional regulation frameworks has been heavily influenced by the US as well as by aspects of the Chinese financial market. First, although financial integration continues to develop, separate operation remains a principle of the current legislation, with the Chinese Securities Law prescribing that the "securities industry should be independent and separately operating with banking and insurance industry". Accordingly, each financial industry currently has its own correspondent regulatory body. Second, China's financial industry has a relatively low degree of liberalisation. There is still much administrative intervention in China, such as its requirements for market admission approval, its financial licensing regime, and new financial services and products approval. Under such a regime, each regulatory entity can easily identify its role and ascertain regulatory liability. However, the regulatory bodies in this manner serve to divide power among financial industries while ignoring the effect this has on financial products and services. ${ }^{22}$

Functional regulation was first proposed by Merton and Bodie, winners of the 1997 Nobel Prize in Economics. Compared to institutional regulation, functional regulation focuses on financial activities rather than institutions. ${ }^{23}$ The theory follows that financial products or services with the same function should be regulated by the same regulator regardless of which financial organisation provides them. This perspective is based on two premises. First, that financial functions are far more stable than financial institutions, and that functions change less over time and vary less across geopolitical boundaries. Second, competition causes regulatory structures to evolve toward greater efficiency of performance in a financial system.

\footnotetext{
${ }^{21}$ Qingxiu Bu, Will Chinese Legal Culture Constrain its Corporate Governance-Related Laws?, JOURNAL OF CORPORATE LAW STUDIES 111 (2015).

${ }^{22}$ Fan Liao, Regulation of Financial Conglomerates in China: From De Facto to De Jure, EUROPEAN Business ORGANIZATION LAW REVIEW 299 (2011).

${ }^{23}$ Schwarcz, Steven, The Functional Regulation of Finance (2014). http://ssrn.com/abstract=2437544.
} 
According to the theory of functional regulation, the objective of public policy is to help financial institutions survive and flourish. ${ }^{24}$

Naturally, both regulatory models have their advantages and disadvantages. However, following the 2008 financial crisis, significant problems associated with institutional regulation were exposed. ${ }^{25}$ First, it is fundamentally a framework designed for traditionally segmented financial markets, and thus has difficulty fitting the new financial market, which includes mixed operations among financial industries, especially given the emergence of innovative financial derivatives. As each regulatory body concentrates on its designated part of the financial system, they may all easily ignore the larger picture. In other words, no single regulatory body possesses enough information and authority to monitor and control systematic risks. In contrast, functional regulation approaches financial regulation from a comprehensive perspective. ${ }^{26}$

Aside from the above, the division of power and responsibilities across different regulatory bodies is not always clear or logical, being based on political considerations or historical reasons, and so causes regulatory gaps or over-regulation. In certain situations involving difficult issues, it is possible for regulatory bodies to shirk their responsibilities as much as possible, leaving the market in a regulatory vacuum. On the other hand, there are situations where regulatory bodies may fight hard over their areas of jurisdiction, which may lead to overregulation and hence significant costs for both regulators and regulatory targets. Institutional regulation theory suggests that each type of financial institution should have a corresponding regulatory body. This may seem like a perfect man-to-man defence, but in reality it has only led to regulatory arbitrage. ${ }^{27}$

Functional regulation theory does not come without shortcomings. Certain researchers have noted that, although the boundary between financial industries has become increasingly blurred at the margins, the core financial businesses of banking, securities, and insurance remain separate. Mixed financial operation would increase risk spreading as well as make the risks too complicated to forecast. Therefore, it would be dangerous if insufficient attention was paid to the differences between financial industries. However, functional regulation theory is nonetheless better

\footnotetext{
${ }^{24}$ G. Paulus, The Wonderful World of Privileges, EuRopean Company AND Financial Law Review 535 (2014).

${ }^{25}$ Ibid.

${ }^{26}$ Datuk Simon Shim, Governance in the Markets: Malaysian Perspective, JouRnAL OF FINANCIAL CRIME 312 (2006).

${ }^{27}$ Hui Huang, Institutional Structure of Financial Regulation in China: Lessons from the Global Financial Crisis, JoURNAL OF CORPORATE LAW STUDIES 244 (2010).
} 
adapted to the realities of modern financial markets than institutional regulation theory, since it dispenses with the traditional boundaries between banking, securities, and insurance. The former represents a modern means of financial regulation to deal with the mixed financial operations and financial innovations of the time. ${ }^{28}$

Nevertheless, we need to understand that functional regulation is not the equivalent of a unified regulator model. Several researchers believe that the greatest advantage of functional regulation is the establishment of a unified regulatory body to regulate all of the financial products and services it would entail. ${ }^{29}$ However, this would be a misunderstanding of functional regulation theory. While it does not divide regulatory power among regulatory institutions, it also does not require a unified regulatory body. In fact, different countries that adhere to functional regulation theory have adopted different regulatory frameworks based on their specific contexts. The UK established a universal regulator, an approach that has been followed by Japan and South Korea, whereas Australia adopted a "twin peaks" model, which assigns regulatory power to two separate regulators. ${ }^{30}$

The establishment of a unified regulatory body does not affect the application of functional regulation. Indeed, different departments among unified regulators must still share information and cooperate. Even the UK's single regulator model does not come without problems. First, there is the concern that a single regulator is far too powerful. ${ }^{31}$ Second, the regulatory responsibilities allocated to a single regulator may be too heavy, causing the regulator to become overloaded and thus reducing regulatory efficiency. By contrast, the division of regulatory responsibility across a number of regulators allows regulatory diversity and specialisation. ${ }^{32}$ Third, a unified regulator may be susceptible to reputational contagion, as one mistake in a single department will damage the credibility of the regulator as a whole. For instance, the Financial Service Authority (FSA) suffered much criticism due to its handling of a single insurance company (Equitable Life). This case ignited much negative publicity about the FSA simply because one of

\footnotetext{
${ }^{28}$ Hui Huang, Institutional Structure of Financial Regulation in China: Lessons from the Global Financial Crisis, Journal of CoRPORATE LAW STUdies 244 (2010).

${ }^{29}$ Ibid.

${ }^{30}$ Hui Huang, Institutional Structure of Financial Regulation in China: Lessons from the Global Financial Crisis, JOURNAL OF CORPORATE LAW STUDIES 244 (2010).

${ }^{31}$ Drummond, Sherry Sours Merger, The Australian FinanCial Review 197 (2008).

${ }^{32}$ Hui Huang, Institutional Structure of Financial Regulation in China: Lessons from the Global Financial Crisis, JoURNAL OF CORPORATE LAW STUDIES 244 (2010).
} 
its departments made a single failure of prudential regulation. ${ }^{33}$ Lastly, it is difficult for a single regulator to exercise all regulatory power and meet various regulatory goals, as the latter may be different in nature and even conflict with one another. For instance, prudential regulation is concerned with the financial soundness of regulated targets, whereas business conduct regulation is concerned with the way in which financial products or services are marketed and sold. Thus, it may be more efficient to have two separate agencies carry out these different regulatory powers. ${ }^{34}$ This is the main reason that Australia has modified the UK's single regulator model to its own "twin peaks" regulator style.

Path dependency theory should also be considered when adopting a single regulator model. According to path dependency theory, today's decisions are limited by the decisions that have been made in the past, and the paths of change are affected by the circumstances that have influenced past decisions. ${ }^{35}$ Thus, it is necessary to perform a cost-benefit analysis of merging China's three regulatory bodies, which may involve large costs that outweigh the corresponding benefits. After all, the current financial regulatory framework was created just a few years ago and so should be given a period of time in which to improve its management. It worth noting that the US has introduced functional regulation to cope with financial modernisation and innovation following the passing of the Gramm-LeachBliley Act of 1999, which permitted financial holding companies to engage in any financial activity, including insurance and securities. Thus, the US regulatory system has features of institutional and functional regulation, namely regulatory entities divided according to financial sectors, although this is compatible with functional regulation. ${ }^{36}$ Accordingly, the current institutionally-based regulatory regime in China can fulfil its regulatory objectives in a similar fashion. The regulatory responsibility of P2P lending can be taken on by multiple regulatory entities. Multiple regulatory entities should oversee online P2P lending platforms depending on the activities that fall with their regulatory authority. Regulatory entities can improve coordination in several ways, for instance via joint conferences, which can also serve to minimise reform costs.

\footnotetext{
${ }^{33}$ Schooner and Taylor, United Kingdom and United States Responses to the Regulatory Challenges of Modern Financial Markets, 38 TeXas InTERnAtional LAW Journal 317, 344 (2003).

${ }^{34}$ Llewellyn, Institutional Structure of Financial Regulation and Supervision: The Basic Issues, WORLD BANK WORKING PAPERS 25 (2006).

${ }^{35}$ Elen Stokes, Book Reviews: The Politics of Blood: Ethics, Innovation and the Regulation of Risk, MED LAW REVIEW 167 (2015).

${ }^{36}$ Rachel E. Sachs, Ensuring the Safe and Effective FDA Regulation of Fecal Microbiota

Transplantation, JOURNAL OF LAW AND BIOSCIENCES 400 (2015).
} 
In conclusion, to ensure that the P2P lending industry is properly regulated and based on the UK's financial regulation history, a unified regulator does not have to be established. Whether the country utilises the "multiple regulators" model of the US, the "single regulator and integrated regulation" model of the UK, or even the "twin peaks and objective-based regulation" model of Australia, functional regulation theory can be utilised to improve the regulation of the country's modernised financial industry, thus ensuring that the same products or services receive the same regulation and so reducing unfair competition.

\section{Suggestions FOR P2P LENDiNG REgUlATION IN CHINA}

Certain researchers have suggested that P2P lending should immediately adhere to the same regulations as traditional financial institutions. Indeed, fraud or the use of $\mathrm{P} 2 \mathrm{P}$ lending platforms to avoid regulation should be stopped, although China must also allow for financial innovations to serve the economy and promote entrepreneurship. Therefore, the objectives of P2P lending regulation should include maintaining financial market order while avoiding the stifling of innovation, maintaining the growth of the P2P lending industry, reducing regulatory arbitrage, and closing legal loopholes.

\section{A. Encourage Financial Innovation}

P2P lending is a financial innovation that can bring greater efficiency and enhanced functionality to the financial system. P2P lending plays an important role in servicing moderate- or low-income individuals and SMEs that are rarely granted loans from banks. Therefore, if regulators maintain an appropriate tolerance for innovation and guide the P2P lending industry down a healthy track, society will be better served. More specifically, China should amend certain laws that may classify P2P lending as illegal. The most important step is to draw a clear line between "illegal crowdfunding" and P2P lending, which would give the P2P lending industry space to develop. Second, time must be given to $\mathrm{P} 2 \mathrm{P}$ lending platforms to adjust to a new regulatory regime. Harsh and immediate regulation may lead the P2P lending market to shrink and suffer curbed financial innovation. The fact of certain P2P lending platforms going bankrupt is a normal market phenomenon and the result of competition, which is beneficial to the industry in the long-run. Thus, regulation must strike a balance between overregulation and risk prevention. China can refer to the UK's history in this regard to establish a transitional period for new regulatory requirements, 
which will offer the platforms time to adjust to the new regulatory regime. ${ }^{37}$

\section{B. Functional Regulation}

P2P lending is a financial service innovation that has led to the emergence of terms such as "democratic financing", "financial inclusion" and "financial disintermediation". ${ }^{38}$ However, fundamentally, P2P lending does not change the function or essence of basic finance. P2P lending changes the form of financial service, yet it does not change the risk control requirements of the financial industry. Therefore, if certain P2P lending models offer the same products and services as traditional financial industries, they should accept the same regulations. At present, there are four P2P-lending business models in China. Aside from the pure online intermediator model, the other three models each allow regulatory arbitrage to a certain extent. With regard to platforms that offer guarantees on refunding investments via their own funds, these involve the offering of guarantees without licensing. As for the securitisation model, P2P platforms are allowed to bypass strict regulations on financial products. As for the model of assignments of credit, P2P platforms and specialised creditors are allowed to bypass the licensing regime as well as rigid regulation. Regulatory arbitrage is unfair to other financial institutions that provide similar products and services. Thus, regulatory bodies must adopt functional regulation to ensure that the same businesses accept the same regulations regardless of whether they are traditional financial institutions or internetbased financial institutions.

\section{Improve the Credit Rating Environment to Reduce Guarantees}

In terms of the nature of $\mathrm{P} 2 \mathrm{P}$ lending, online information intermediation is the core innovation of an industry that differs from traditional finance. As P2P lending platforms provide unsecured loans to borrowers, credit is key. Platforms that express or imply guarantees not only reduce the efficiency of the industry, but, more importantly, incur higher risks for the platforms themselves and the entire financial system, as well as violating relevant laws related to guarantees and requirements for financial institutions. To rid the industry of poor guarantees, the first step is to expand credit assessment channels for the P2P lending industry. With better credit

\footnotetext{
${ }^{37}$ Emily Reid, The Future for Peer-to-Peer (P2P) Lending: The Proposed Regulatory Framework for Lending Platforms, JOURNAL OF INTERNATIONAL BANKING AND FinANCIAL LAW 38 (2014).

${ }^{38}$ Shiller R., FinANCE AND the GoOd Society 135 (Princeton University Press 2012).

${ }^{39}$ Brian Donnelly, Crowdfunding Gathers Pace, Mortgage FinanCE GazeTte 44 (2014).
} 
rating information, P2P lending platforms can sift through several unqualified borrowers, avoid repeat lending, and in turn reduce likely default rates, thereby enhancing investor confidence. ${ }^{40}$

First, P2P lending associations should work toward the creation of shared credit databases, not only for the sake of improving efficiency, but also to avoid vicious competition due to repeat lending. This can be initiated by building shared blacklists. Second, the Chinese Central Bank credit system should lend access to the P2P lending industry. Many P2P lending platforms consider big-data mining the key to credit assessment, seeking to analyse user needs and risk characteristics. However, data mining should not be identified as simply the processing of existing data, but rather be utilised to create new and valuable insights into risk indicators, which will then help to predict the overall creditability of borrowers. This will require the sharing of borrowers' debt and credit records through close cooperation with credit authorities, industry associations, and third-party credit organisations. The use of big-data mining to assess creditability will be hard to realise in the short-term in China, and the development of a comprehensive credit database will require an enormous amount of time and investment that no single industry can undertake. In addition, the P2P lending industry can provide abundant information on the credit information of SMEs and individuals to the Central Bank credit system so as to enrich its representativeness. Such information will be a useful complement to the Central Bank's credit system because it has not previously included credit information on SMEs. Although this data is fragmented and isolated due to being stored in different platforms, a comprehensive civil credit database might be formed if it could be collected. ${ }^{41}$

\section{CONCLUSION}

Admittedly, China's P2P lending industry has developed with substantial risks. The absence of a regulatory system has led to a lot of poor quality products or services in the market, which has in turn affected the development of the P2P lending industry and endangered the stability of the whole financial system. Without proper regulation, P2P lending may cause systematic risks in the financial sector, including fraud and money laundering, and so harm investors' interests. However, P2P lending has

\footnotetext{
${ }^{40}$ K. Osuji and C. Amajuoyi, Online Peer-to-Peer Lending: Challenging Consumer Protection Rationales, Orthodoxies and Models?, JouRnal of Business LAW 490 (2015).

${ }^{41}$ K. Osuji and C. Amajuoyi, Online Peer-to-Peer Lending: Challenging Consumer Protection Rationales, Orthodoxies and Models?, JouRnal OF BusinEss LAW 491 (2015).
} 
played a significant role in breaking the bottlenecks in business financing in China, since due to the ignorance of traditional financial institutions, the capital needs of SMEs and individuals cannot be satisfied, while the low operating costs and high efficiency of P2P lending platforms can perfectly match their needs. Therefore, the healthy development and stability of the P2P lending industry is important to China's economy. The government and the industry's self-regulation associations should provide guidance to ensure further healthy development and standardised operation of P2P platforms, and a detailed P2P lending industry regulatory system should also be established in the near future.

There are a lot of international regulatory experiences, including selfregulation and governmental regulation, which China can refer to, such as using functional regulation in order to eliminate regulatory arbitrage and promote healthy development in the long run. However, there is no need for China to merge all the existing regulatory entities into a single unified regulator. The functional regulation is not simply equivalent to the unified regulator model. Sector-based regulatory entities can also function well in terms of P2P lending regulation.

To promote the healthy development of P2P lending in China, a lot of work must be accomplished in the near future. First, the government should adopt an encouraging and supportive attitude towards this emerging industry, offering appropriate tolerance for its present problems. Some legislation needs to be revised in order to differentiate P2P lending from illegal fundraising, as well as to protect investors' interest and confidence. The functional regulatory model must be integrated into P2P lending regulation in order to reduce regulatory arbitrage, ensuring that similar financial services receive similar regulation. 